\title{
Research assessment as governance technology in the United Kingdom: findings from a survey of RAE 2008 impacts
}

Alis Oancea, University of Oxford

In: Zeitschrift für Erziehungswissenschaft, 17(6), pp 83-110.

The final publication is available at Springer at DOI 10.1007/s11618-014-0575-5.

\section{Abstract}

This paper uses empirical research data and theoretical insights from the literature on governance to problematise some of the arguments presented in the research assessment literature, in particular, the description of the UK RAE/REF as a mechanism for top-down control with strongly negative, blanket-impacts on disciplines, institutions and individual researchers. The concepts of performativity, accountability and governmentality are employed to unpack normative claims about negative impacts and conflicts of values, and empirical claims about the nature of changes in behavior, attitude and interpretation, as reported by the researchers surveyed. The paper argues that inherent, multiple ambivalences of the RAE as a governance technology operate at the transition points between traditional and contemporary forms of governing and account for the mixed picture of its impacts at system, field, institutional, and individual level.

\section{INTRODUCTION}

The public funding of higher education-based research in the United Kingdom has been for a long time known as the "dual funding" system. In this system, "QualityRelated" (QR) core block funds for research infrastructure are allocated to institutions by the higher education funding councils (HEFC) for each of the countries of the UK (for example, the Higher Education Funding Council for England - HEFCE). Further funds to cover direct research costs, on a project or programme basis, are made available through competitive grants run as a separate funding stream by seven Research Councils. The allocation of the core block grants is based on HEFC formulae, in which a crucial variable is the outcome of the UK-wide research assessment exercises (RAE, now REF - Research Excellence Framework) held roughly every 4-6 years, since 1986.

The RAE was introduced in 1986 as a research selectivity exercise and redesigned in 1989 to a format that, with some review and recalibration (see e.g. Roberts, 2003), continued through the 1992, 1996, 2001 and 2008 rounds. The exercise has recently 
been rebranded as the REF, due in 2014; while REF is similar to the RAE in most aspects, it has brought a major change that is creating ripples throughout the higher education systems of the UK: the introduction of non-academic impact of research as a domain of assessment, alongside research outputs and research environment.

The main purpose of RAE 2008, as specified in the official guidance (RAE 03/2005), was to produce quality profiles for each subject-focused submission of research activity made by institutions, covering quality of outputs, environment and esteem (all between 1 January 2001 and 31 July 2007). These profiles were then used by the Funding Councils as part of their formulae to determine the size and allocation of core grants to research institutions from 2009-10. Although the RAE also had clear implications for institutional research strategies, behaviour and benchmarking, these implications were not acknowledged explicitly as part of the RAE statement of purposes.

The profiles were produced through informed peer review of submissions, using the criteria of originality, significance and rigour, by 67 subject sub-panels, grouped in 15 main panels of cognate disciplines. The quality profile was based on a scale, from one star (national recognition) to four stars (world-leading), with a separate "unclassified" category for work that either fell below the national standard, or did not fit the RAE definition of research as "original investigation undertaken in order to gain knowledge and understanding" (RAE 3/2005).

Educational research was assessed by sub-panel 45, which, alongside Psychology and Sports-related Studies, was part of main Panel K. As calculated by Whitty et al (2012) using Higher Education Statistic Agency and Higher Education Funding Council data, RAE submissions amount to about $75 \%$ of the number of higher education institutions with education studies provision, and to about $31 \%$ of the fulltime equivalent staff employed in education units in the country. In the words of the chair of the education sub-panel, its work had been an attempt to make the best of a top-down framework, a process that required building temporary bridges over paradigmatic, philosophical and practical concerns: "given that the elected government has come up with this process then the education sub-panel, whatever its collective and personal concerns, will try to grasp the nettle and carry out the task to the best of its ability, hopefully dispensing justice with mercy" (Brown, 2007:356). 
The use of quality profiles, mapping the proportion of research submitted by each institution that was deemed by the panel to fit each rung of the scale, was an innovation of RAE 2008, as in previous exercises the outcome for each institution had been expressed as an aggregate grade. The expectation, early in the process, was that the profiles would enable a move away from the league-table ranking that was produced by previous exercises, and also that it would enable "finer-grained" QR funding allocation to "reward excellence wherever it was found" (HEFCE, 2009). In actual fact, the ranking still happened, with, for example, the Times Higher Education using the profiles to calculate a Grade Point Average (GPA) for each institution as a basis for discipline-specific "tables of excellence" (THE, 2008). As for the wider distribution of funds, while in England in 2009-10 the grants followed the profiles, with different weightings for each quality level (except $1^{*}$ ), in 2010-11 and 2011-12 the weightings were changed in favour of higher concentration of funding around $4^{*}$ research, and in 2012-13 funding for $2^{*}$ research ceased entirely. Additional measures have been used throughout the period to protect the funding for natural sciences, engineering, medicine and mathematics, plus, since 2010-11, parts of psychology and geography.

There is a growing body of literature, including empirical studies, on the assessment exercises and their influence on structural and qualitative re-arrangements of disciplinary, institutional and national research systems in the UK. This literature engages critically with the purposes of the exercise (Ovseiko, Oancea and Buchan, 2012, Webb, 2005, Harley, 2002), its technicalities (Ovseiko, Oancea and Buchan, 2012, Brown, 2007, McNay, 2003), and its consequences for fields of inquiry, institutions and researchers (Oancea, 2010b, Furlong, 2013, Brown, 2008, Oancea, 2008, Dadds and Kynch, 2003, Thomas, 2001, Henkel, 2000, McNay, 1997), including psychological and behavioural implications (Holligan et al, 2011, Harley, 2002, Talib, 2001, Elton, 2000, Warde, 1996). These critiques suggest that the RAE/REF has a number of commendable features, such as its early emphasis on sustaining research diversity and emergent research cultures, the more recent exhortations for institutional collaboration, and, more generally, its procedural transparence, and its fundamental reliance on subject-specific peer review (Bridges, 2009). However, most commentators describe the exercises as costly, burdensome, and damaging research governance and administration, research quality and diversity, research capacity and work climates, and the nexus between research and teaching (Oancea, 2010a reviews these criticisms in detail). Studies of assessment 
exercises in other countries also highlight a complex, though mainly negative, picture (e.g. Currie, 2008, on Hong Kong).

This growing body of literature, described by Lucas (2006) as "atheoretical", has began to make theoretical moves, for example by setting the RAEs in the frameworks of, say, neoliberalism, New Public Management, and global research economies. Some of this work uses the relationships between notions of performativity, accountability and governmentality in an attempt to make sense of the contradictions apparent in the evolution of research assessment as a policy tool, and in the responses it has elicited within academia (e.g. Besley and Peters, 2009; Coryn, 2009; Oancea, 2008, 2007; Epstein et al, 2008; Donovan, 2005; Morley, 2003; Olssen, 2002; Power, 1997).

Performativity, accountability and governmentality are all polyvalent terms. Inspired by Lyotard (1984), "performativity" refers to a new "language game" that legitimizes science in terms of "the best input/output equation" (p.37); as a governing technology, the assessment and sanctioning of research performance plays on this form of legitimization to regulate access to public resources. "Accountability" points to both hierarchical "holding to account" for, and relational "giving of an account" of, action (Ranson, 2003) - an inherent ambivalence that makes it "a political technology: a duplicitous concept" (Shore and Wright, 2004, p. 202). In Besley and Peters' (2009:32) view, the tensions surrounding "managerial" and "professional" accountability are illustrative of the "inherent conflict between neoliberal managerial and liberal professional culture" in higher education institutions (see also Olssen, 2011, and Power, 1997). "Intelligent accountability" arises from twin commitments to freedom and truth, and consists of "substantive and knowledgeable independent judgement of an institution's or professional's work" (O'Neill, 2002: 58). Finally, following Foucault, the literature on "governmentality" analyses the complex intersections between freedom and domination, consent and coercion, exchange and competition, empowerment and dependency in contemporary governmental practices (including practices of self-governing), as well as the historical continuities and discontinuities that are connected with their genealogies (Deane, 2010). According to Foucault,

"in the broad meaning of the word, governing people is not a way to force people to do what the governor wants; it is always a versatile equilibrium, with complementarity and conflicts between techniques which assure coercion 
and processes through which the self is constructed or modified by himself". (Foucault 1993, 203-4).

In a context of shrinking research funds, there is renewed debate around the inevitability and effects of the mechanisms of competition, concentration and selectivity built around the RAE. For example, Kelly and Burrows (2012) summarise the impacts of the RAEs as "performative metricisation" and "financialisation" of higher education research, with wide, inescapable implications:

Once released, the [RAE] data takes on a reified form and also develops an autonomous 'public life'. It is not only used to inform funding allocation decisions. It is inserted in other secondary algorithms used to determine the eligibility to apply for certain types of research and postgraduate funding. It is used as a rhetorical device by institutions in their prospectuses, on their websites and in their funding bids. It feeds into myriad aggregate league tables manipulable via web 2.0 applications by students, industry, colleagues, government, the media and so on. Some of us celebrate the outcomes; others are forced to rethink their strategies; others still are closed down. But, in the end, we are all implicated and some come to realize that this is a performative 'game' from which it is almost impossible to escape (p. 140).

In the same vein, Shore and Wright (2000) warn against "the rapid and relentless spread of coercive technologies of accountability in higher education", leading to the creation of "self-managing individuals who rend themselves auditable" (p. 57). The RAE is one such technology, through which 'the 'good researcher' is discursively produced via performance indicators linked to audit" (Morley, 2003, p. 25).

This paper uses empirical research data and theoretical insights from the literature on governing and performativity to assess some of the arguments presented in this debate. The paper unpacks both normative claims about "negative" impacts and conflicts of values, and empirical claims about the nature of changes in behavior and interpretation in a RAE context, as reported by researchers. In particular, it problematizes the (roughly put) idea that the RAEs are a mechanism for top-down state control, with strongly negative blanket-impacts on disciplines, institutions and individual researchers.

The paper argues instead for an interpretation of the exercise as a multiplyambivalent technology that operates at the transition points between traditional and 
contemporary forms of governing: it "recodes" and recombines practices of authority (such as punitive sanctions, for example through withdrawal of funding), discipline (such as regulation and administration of academic work) and government (such as functional "optimization" of institutional activity and use of resources) (Dean, 2010: 28-29, drawing on Foucault, 2007:107-109). From this perspective, technologies like the RAE operate a mix of sanctioning and incentivising, of disciplining, antidisciplining and self-disciplining, of dividing and connecting, of defining and loosening boundaries between modes of knowledge and forms of practice. These ambivalences make them compatible with new types of "soft" governance, characterized by "networks" of "social and political communication" that blur the boundaries between the public, private and voluntary sectors, and by "recursive practices" of steering, dialogue, self-organisation and regulation, integration and coordination (Bang, 2003:20).

\section{THE STUDY}

The findings described in this article arose from a study of the impacts of RAE 2008 on education research in all countries of the UK. The study was commissioned by the British Educational Research Association and the Universities' Council for the Education of Teachers through competitive tendering in August 2009 and was carried out between September 2009 and January 2010; the initial report, on which this paper is based, was Oancea (2010b). It explored the perceived influences of RAE 2008 outcomes and processes on a) individual departments of education; b) different groups of staff in departments of education; and c) education research as a field (as perceived locally).

Three sets of data were analysed in the study: secondary data from the RAE 2008 submissions and outcomes database; primary data from a survey of 30 education departments (distributed through internal departmental email lists); and primary data from a series of interviews in a further 9 institutions. This paper reports findings from the survey component, with particular emphasis on the qualitative analysis of participants' (sometimes very detailed) responses to open-ended questions. The survey was intended as a source of insights to feed into the design of the interview component, as well as a way of capturing a wider diversity of views about the RAE. It consisted of multiple-choice and scaled questions, as well as open questions with 
generous space for respondents to express their views. Examples of questions used in the survey are included in Appendix 1.

The survey sample of 30 departments (I will use "department" as a shorthand for "research unit" throughout the paper) was drawn from the 82 submitting institutions to RAE 2008. The sampling procedure was based on several criteria:

1. Geographical location - to ensure coverage of all home countries - the final sample included 23 English institutions, 3 Scottish, 2 Welsh, and 2 from Northern Ireland;

2. Historical type of institution - to ensure coverage of older, civic, former polytechnic, and newer institutions, as well as of different mission groups, to which institutions may be affiliated;

3. RAE 2008 profile - to cover the whole range of RAE quality outcomes;

4. RAE 2001 results - to capture historical variation in research support and cultures.

The sample comprised of staff in education departments in 15 pre-1992 and 15 post1992 institutions. ("Post-1992" refers to institutions that became universities at the earliest under the 1992 Higher and Further Education Acts, which abolished what had previously been known as the "binary divide" between polytechnics and universities, thus effectively enabling polytechnics to become universities.)

The survey received 131 responses, amounting to a $20 \%$ response rate (of the total FTE entered to the RAE by the participant institutions). Based on responses to biodemographic questions (see Appendix 2 for full sample description), the typical respondent to the survey would likely be a senior lecturer $(37 \%$ of the total respondents) based in an English (81\%) pre-1992 HEI (81\%), on a permanent contract $(86 \%)$, possibly with some decision-making responsibilities $(49 \%)$, with $\mathrm{PI}$ experience of funded research (57\%), possibly aged 55-60 (31\%), and female (52\%). Her work would have been submitted to the 2008 RAE (74\%). She would tend to work in ad-hoc teams (35\%) on multi-disciplinary projects (65\%), would have good/average knowledge and experience of research assessment, a positive view of the research environment in her own department (61\%) and possibly an optimistic view of its future $(40 \%)$. Thus, the findings from the survey need to be read with some caution, due to the relatively low number of respondents and to the inevitable fact of their self-selection. 
The study had ethical approval from the University of Oxford. Given the sensitive nature of the topic, all reasonable efforts have been made to ensure the nontraceability of any of the quotes included in this paper to individual respondents and their institutions.

\section{FINDINGS: SPECIFIC AREAS OF PERCEIVED IMPACTS}

\section{Perceptions of impacts on individual work and careers}

$87 \%$ of the respondents to the survey reported that RAE 2008 had influenced, in one way or another, their individual work and career, including the quality of their research, promotion prospects, earnings, likelihood to obtain further external funding, quality of publications, sense of belonging to a research culture, engagement in applied or in interdisciplinary research, collaborations with practitioners, and knowledge exchange activities. On balance, the most favourable influence (i.e., an increase in individual prospects or engagement for that item) reported was on the quality of publications; the least favourable influence (i.e. a decrease in prospects or level of engagement) was on the quality of teaching (see Appendix 1 for the full survey question). The strongest reported impact of the RAE was on individuals' sense of belonging to a research culture in the department $(74 \%$ of respondents identified some form of impact). The area seen as having been least influenced by the RAE in any way was earnings (73\% reported "no impact"). Figure 1 charts the responses of those who perceived RAE 2008 to have had some impact (be it positive or negative, as opposed to "no impact") on each item surveyed, as percentages of the total number of survey respondents $(n=131)$.

Figure 1. Reported influences of RAE 2008 on individual work and career (as \% of total respondents, $n=131$; see response scale in legend) 


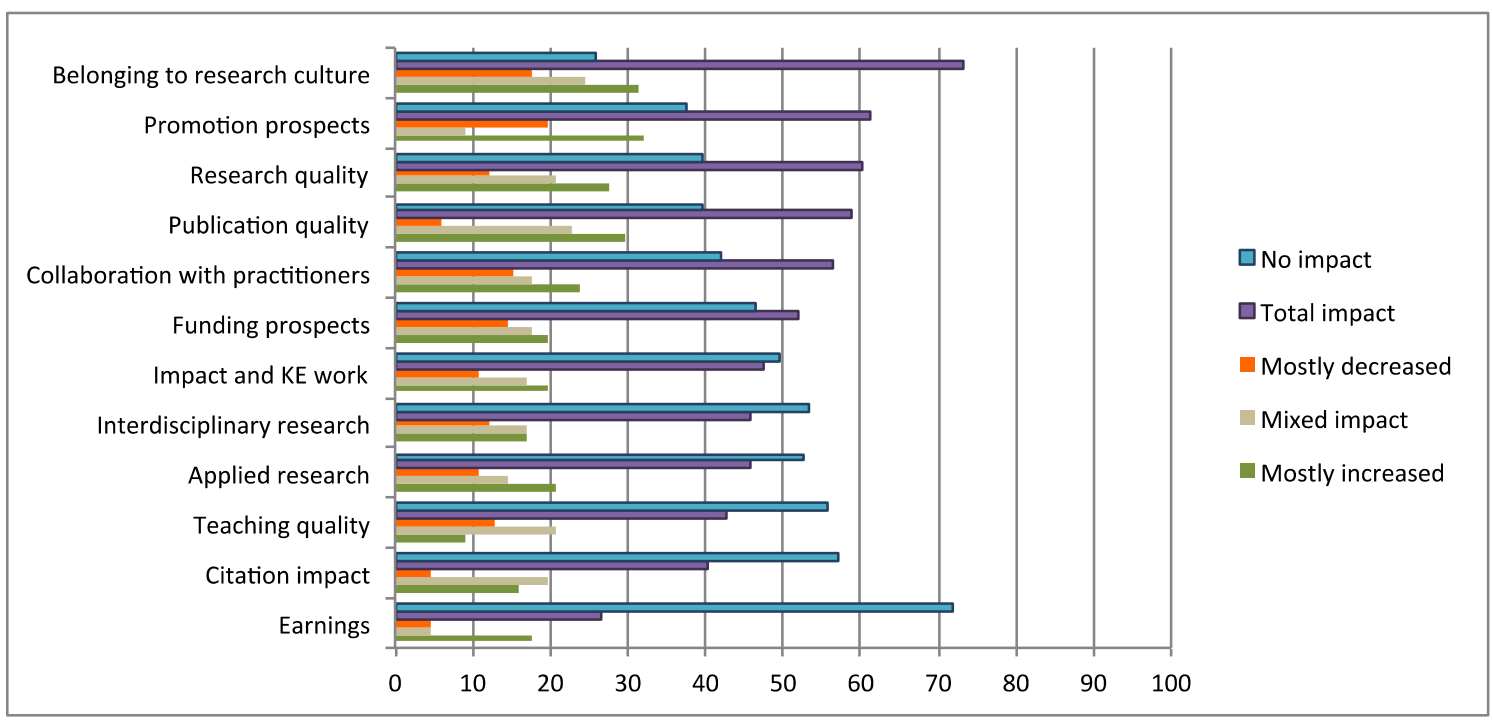

In their responses to further, open-ended questions (see Appendix 1), 59\% of the total number of participants provided details on positive impacts of the RAE. Respondents commented on the impacts of RAE processes on improved support for their research in a stronger departmental research environment. This support included new mechanisms for recognition of research efforts, allocation of resources, and research management. One respondent identified three areas of positive impacts:

"I. Recognition by [research unit] of the nature and expectations of research activity - engagement with strategy for research has been greater. II. Recognition in [HEl] of the contribution of educational research to the wider profile - reassessment of funding allocations to underpin resource needed to continue our work. III. Recognition of the wide range of activity - publication, contribution to the community, research environment - which is needed to support high quality research" (professor, post-1992 institution).

These processes were coupled with RAE-driven increases in publication productivity:

"It does make you get up and write up research for publication - well as many publications as possible" (fixed-term researcher, pre-1992 institution).

Being included in the RAE submission and sharing in good results was seen as key to academic promotion and to a range of other employment-related benefits, such as competitive advantage in recruitment and transfer, workload management, and, indirectly, pay:

"I don't think I would have got my promotion without being included in our UoA submission" (senior lecturer, aged 30-40, pre-1992 institution) 
"I am a researcher with outputs and this made me valuable on the job market so I was promoted" (professor with core management responsibilities, pre1992 institution).

In addition, respondents (in particular, those whose work had been entered to the $\mathrm{RAE}$ ) reported positive influences on their motivation, confidence, and identity as researchers, including:

enhanced "sense of myself as a researcher" (senior lecturer, pre-1992) and "understanding what counts as quality" (lecturer, pre-1992);

"enhanced sense of being part of the research community within the institution and nationally" and "increased confidence in conducting and publishing own research" (professor, university college);

higher status, esteem and recognition, "in the university and wider research community" (senior lecturer with management responsibilities, pre-1992);

Nonetheless, $24 \%$ of these respondents were keen to qualify their positive assessment. Rather than attributing impact directly to RAE 2008, they placed it in the context of "intrinsic professional motivation", of job descriptions (work that would have been done anyway), of the cumulative impact of successive RAEs, and of the role of other factors, in particular the research councils, government funding, and technological developments (e.g. in bibliometrics). In the views of these respondents, if anything, RAE 2008 had been a catalyst, rather than a cause, of the positive developments described. In one respondent's words,

"it is hard to say what came about because of what and whether any or all of the above was as a result of the RAE or I would have done such things anyway" (professor, post-1992).

Respondents tended to be more trenchant in attributing negative impacts to the RAE (with only $1 \%$ of those who gave examples of negative impacts choosing to qualify them) - although some were also keen to point out that in their view the RAE was a much more "enlightened" system than those used in other countries. Many reported struggling to work and develop in what they saw as a RAE-driven climate of excessive pressure (in particular, to publish), unreasonable workloads, competition (rather than collaboration), rivalry rather than collegiality, short-termism, conformity rather than creativity, and game-playing: 
"The pressure that is being exerted by my university, faculty and school is extensive in regard to number of publications, sole authorship and status/ impact of publications." (senior lecturer, pre-1992 institution, Russell group)

In particular those academics whose research had not been submitted to the RAE felt demoralized by the processes leading up to the RAE submission - undervalued, less motivated, anxious, dispirited, depressed, and having a

"sense of professional exclusion - recognising that the powerful in my institution had selected the focus of the research that would be submitted" (senior lecturer, post-1992 institution).

For example, $31 \%$ of respondents whose work had not been submitted reported a weaker sense of belonging to a research culture post-2008, compared to only $11 \%$ of those whose work had been submitted. Responses to the open questions indicate anger at what some respondents from this group saw as unfair distribution of workload during preparations for submission:

"I felt angry when I had to pick up work from colleagues who were purportedly being freed to do research" (senior lecturer, mid-management, pre-1992 institution).

These findings echo those of McNay, 1997, Thomas (2001), Morley (2003), Warde (2006) and Holligan et al (2011) on the negative emotional responses and psychological consequences of the RAE and other audit systems in higher education.

Respondents whose work had not been submitted to the RAE expressed concern about the impact of the exercise on their opportunities for promotion and professional development: $55 \%$ percent of this group reported a belief that their promotion prospects were weaker post-2008 (while only 16\% believed their prospects were better now), a feeling in sharp contrast with that of respondents whose work had been submitted, who felt that their promotion prospects had improved as a consequence (40\% improvement and $8 \%$ weakening). Some attributed to not being included in the RAE the subsequent failure to secure permanent academic appointments or promotions, despite what they described as excellent contributions to teaching and other areas of academic activity. They felt that the selection process had included an unacceptable degree of "arbitrariness", the outcome of which undermined their "academic identity" (Henkel, 2000), with likely negative consequences for their current and future academic activity and standing: 
"Feeling that work that I have developed over a number of years has been a waste of space. ... I will take retirement sooner than planned" (senior academic, not included in RAE submission, pre-1992 institution)

"My professional self-esteem as a researcher was undermined because my publications were not entered for the RAE. My motivation to contribute to the RAE was diminished because the work I did appeared not to be valued by my own institution. My sense of identity as a longstanding contributor to subjectspecific professional dialogue, research and publication was affected" (anonymous).

Individuals also reported negative personal impact of RAE-aggravated tensions among different groups of staff. According to respondents' reports, staff who had not been part of RAE submissions were labeled research "inactive" (code for "secondclass citizens"); in contrast, some staff, who had been submitted to the RAE, were labeled "academics" (meaning "non-practitioners", "not part of the community" of teacher educators - lecturer, pre-1992 institution) and "elites" (meaning “cliques").

Under the influence of RAE processes, staff whose work had not been entered to the RAE reported feeling demoralized, devalued or disempowered (39\% of staff from this group indicated so in their answers to the relevant open question, compared to $11 \%$ of respondents whose work had been entered in the RAE). In addition, under the influence of RAE outcomes, staff whose work had been part of highly-ranked submissions that attracted no matching level of funding (particularly in pre-1992 institutions) reported a sense of disillusionment and anticlimax. Staff from all groups described feeling constantly scrutinized, "commodified", and lacking control over their professional activity. All groups also expressed concern with the unreasonable work/life balance required in order to achieve and maintain that position, and with difficulties in career planning. They were particularly dissatisfied with the perceived institutional pressure on part-time and early career staff to produce similar quality and quantity of output to full-time senior staff, who were described as having less teaching-dominated workloads and more opportunities for research support.

The RAE and the way it had been managed in institutions were perceived as having directly affected publication and grant-seeking behaviour. While productivity may have increased, outputs were seen as not only of questionable quality (rushed, rehashed, salami-sliced, strategically timed etc.), but also skewed towards particular formats, audiences, and outlets (mainstream journals, rather than professional 
publications and books). Perceived pressure to produce four "mainstream" outputs detracted from other types of academic communication:

"The push to publish in certain journals distorts the sort of writing and the value it is given" (senior lecturer, management role, pre-1992 institution)

"As my research/writing time was very limited, I had to prioritise writing for peer-reviewed, international journals rather than professional journals or textbooks for pupils, but the latter are more likely to impact on the quality of education in the short term" (lecturer, pre-1992 institution).

More importantly, the RAE (mediated via institutional and departmental management of relevant processes) was thought to have influenced individual decisions about the nature of the research being pursued (see also Harley, 2002). Respondents argued that the exercise and its outcomes disincentivised individual engagement in certain forms and areas of research, such as interdisciplinary research, exploratory and innovative work, "pure" research, philosophical enquiry, and, more generally, other fields of research that did not attract large external funding or did not fit easily departmental strategies for achieving and supporting "critical mass":

"Pressures to conform to narrowing conceptualisations of research and writing. Culture of safety and conformity rather than innovative scholarly enquiry" (professor, mid-management role, pre-1992 institution, 1994 group)

"[The RAE] limited the breadth of projects in which I got involved: the need to publish according to RAE criteria shaped my research decisions" (lecturer, pre-1992 institution)

"Reduction in funding post-RAE 2008 has reduced my research time, increased my teaching time and forced me to research outside my field to bring in research grants" (lecturer, management role, pre-1992 institution)

Although it was not seen as the only reason why pressure to engage in externallyfunded research and be productive was being exercised on staff, the RAE had served as a mechanism for legitimizing, prioritizing, and implementing internal research strategies. Work climate issues were compounded by institutions' attempts at micro-managing RAE processes and, by extension, the broader research activity and environment of a university or a department. The respondents described

"increased attempts to manage research activity at institutional levels centrally plus at Faculty and Department level... Examples include meaningless attempts to try to increase internal research collaborations at the 
expense of external activities in a bid to improve research culture" (professor, management role, post-1992 institution, former polytechnic).

In this context of excessive - some said "obsessive" - focus on research activities (most visibly so in "research intensive" institutions), engagement in, and the quality of, almost all other academic and academic-related activities suffered. The areas that respondents described as having suffered included teaching, pastoral work and student support, supervision, curriculum development, CPD, user engagement activities, administration, and other general scholarly activity. Teaching was deemed the worst hit area - the RAE was seen as creating and legitimising a context in which teaching was devalued and routinised, time was taken away from it (thus creating work overload and discouraging innovation), and associate staff was "bought in", in an attempt to compensate for the conflicting demands placed on the time of regular staff:

"Less scope and time for innovative teaching. Less opportunity for curriculum development initiatives with schools" (senior lecturer, management role, pre1992 institution, Russell group).

"The net effect is that I do less undergraduate teaching, and have to make compromises in teaching and student support that I would prefer not to make, and that my conscience tells me are unsupportable" (senior lecturer on open contract, pre-1992 institution, Russell group).

\section{Perceptions of department-level impacts}

Perceptions of department-level direct and mediated impacts of RAE 2008 were generally stronger than those of individual impact; as indicated in Figure 2, a minimum of $60 \%$ of respondents reported some form of impact of the RAE on all items surveyed. Among those respondents who saw some impact, the most favourable perceptions were those of RAE 2008's impact on the development of departmental research cultures (44\% saw it strengthening under the influence of the RAE) and on research quality (37\%), followed by research capacity, opportunities for early career researchers, and the volume of externally-funded research in the department (each with $31 \%$ of respondents noting increases under the influence of the RAE). $58 \%$ of the total number of survey respondents also gave details of some positive impacts in response to the open question inviting them to do so. Strong negative impacts were identified on researcher morale across the unit $(40 \%$ of respondents saw the RAE as lowering morale), followed by teaching quality ( $21 \%$ of respondents). 
Figure 2. Reported influences of RAE 2008 on departments

(as \% of total respondents, $\mathbf{n}=131$; see response scale in legend)

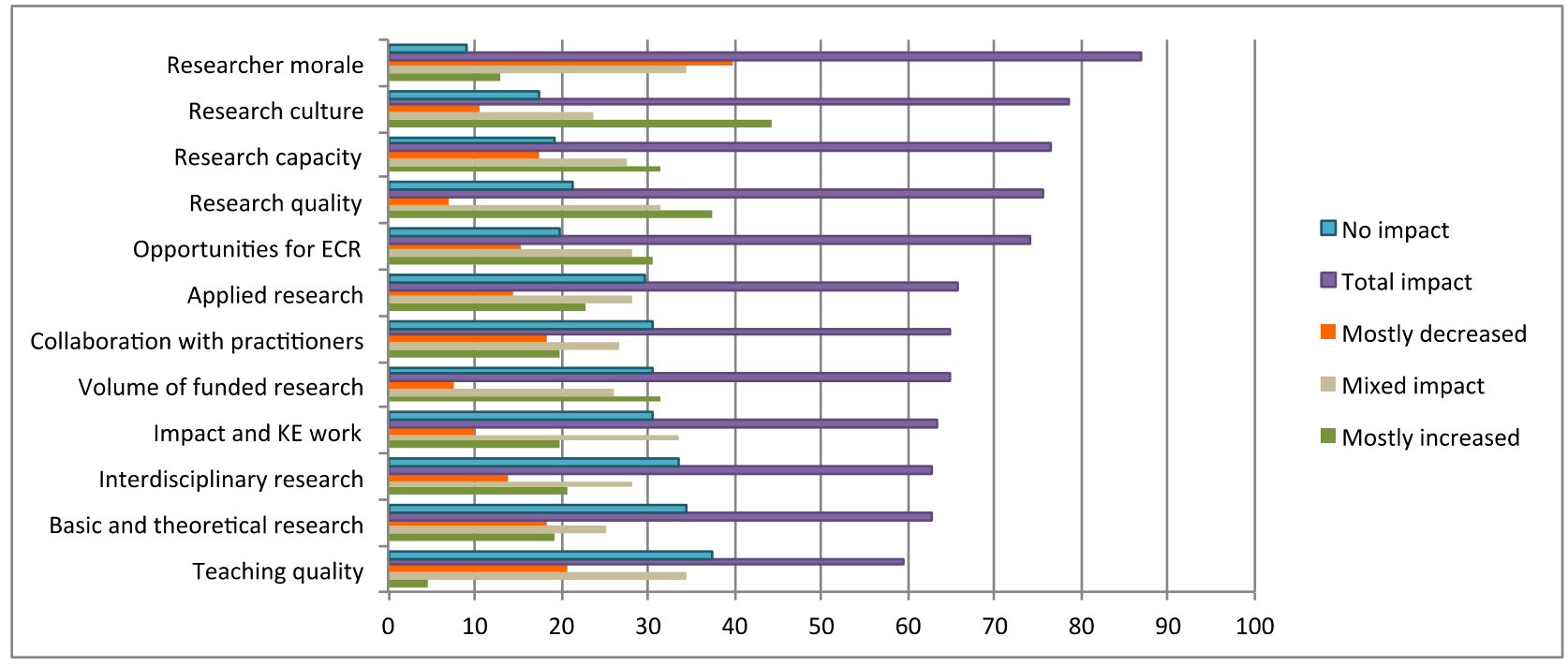

In their answers to further, open questions about the positive and negative impacts of RAE 2008, respondents reported improvements in research organization and management. These changes included better organisation of, and support for, research groups; improved workload management, or at least better awareness of the need to balance time for research against other demands on academic staff time; increased numbers and better experience of research students; improved relationships with the $\mathrm{HEI}$, of which the department was a part; and the introduction of support schemes (e.g. mentoring, study leave, workshops on writing and bidding, seminars). Most of these changes arose as part of preparation for RAE 2008, but in previously unfunded departments they gathered momentum after the allocation of funds post-RAE:

"In my current teaching-intensive university the RAE 2008 has given us our first core funding for research since 2001. We are now able to use this money to support early career researchers and to strengthen our emerging research culture" (professor, departmental management role, post-1992 institution).

The financial benefits post-RAE (such as gaining renewed or first-time QR funding and improving the likelihood of attracting external research income) were attributed to a combination, partly influenced by the RAE itself, of dedicated support for funding applications, more vibrant overall research culture, and gain in reputation (sometimes simply from having been involved in the RAE, but mostly from achieving good ratings). For respondents from pre-1992 departments, the financial outcomes connected with good RAE 2008 results affected directly their ability to use resources 
to maintain past levels of activity and replace staff who were either leaving or retiring. They also saw RAE success and ongoing QR income as a partial buffer against the full effects on their institution of the wider financial crisis:

"The success of the department in the RAE has increased the respect and profile of the department across the [HEI]. This does have some small advantages in the tough financial times currently holding" (head of department, pre-1992/ Russell group institution).

Success in the RAE strengthened reputation and recognition at all levels - among colleagues, institutionally, nationally, internationally:

"The department did well and has gained recognition as a result, nationally and in terms of internal university politics - i.e. across the [unit], not just amongst active returned researchers" (professor, departmental management role, post-1992 institution).

Another area influenced by the RAE was the development of departmental capacity for research. In particular, respondents described mechanisms for supporting early career research staff and initial teacher education staff in engaging with research, writing for publication, and applying for funding. They also mentioned staff development initiatives and the recruitment of new staff with experience of, and/or potential for, research.

Although more difficult to gauge than the impact of the RAE on more visible aspects of the departments, such as staffing and research groups, the impacts of the recent exercise on the culture of an individual department were of the greatest importance to participants. In particular, respondents reported positive impact of RAE 2008 on research cultures (particularly in the case of "emerging" research cultures). The RAE was perceived as having influenced favourably the extent to which (good) research was valued in the department, and having stimulated clearer articulation of a research vision and strategy. It had also encouraged more collaborative work and improved communication among colleagues. The following quotes illustrate these views:

"There is a research culture in the [research unit] - which I would say did not previously exist. Research is taken seriously; study leave is given; nonresearch active members of staff are now becoming more research active" (senior lecturer, not included in RAE 2008 submission, post-1992 institution)

"It was a teacher dominated culture and the RAE was used to force people to take research more seriously. The need for collaboration has been 
recognised and groups, supported" (professor, departmental management role, pre-1992 institution).

Those respondents based in departments that had achieved good RAE 2008 results (particularly in those cases where no large financial loss had been experienced post2009) reported a boost in collective morale, including a shared sense of achievement, motivation to carry on doing research, and a more confident management team:

"Feel good feeling after good results - "proof" that we are as good as we thought we were! Enthusiasm to undertake research; able to use data in publicity for department" (administrator, pre-1992 institution).

However, the positive picture described above needs to be balanced with the $42 \%$ of the total number of respondents who said that they could think of no specific positive impacts, that any positive impacts were the result not directly of the RAE, but of other initiatives that may have been more or less connected with the processes leading to the RAE, or that seemingly positive impacts were in fact double-edged:

"There have been great efforts to create research groups in the Faculty to support a research culture, which has worked to some extent. But in other ways these can seem a constraint, limiting broader opportunities. They also have become vehicles to drive forward the REF, which is both positive and negative." (lecturer, pre-1992 institution).

There is evidence that many of the $58 \%$ of respondents who did mention some positive impacts also shared the latter view. Many were careful to qualify their positive assessments in the space provided by two open-ended questions about departmental impacts. For example, one respondent stated:

"We are certainly concentrating available research funds on a smaller group of more clearly research active staff, but this would happen with or without the RAE. Benchmarking against other institutions is probably a useful bargaining tool in securing a profile for the department and an acceptance of its importance." (professor, department-level managerial responsibility, post1992 institution).

When asked to mention the most significant aspects of their department that had been negatively influenced by RAE 2008, respondents seemed less inclined to qualify their attribution of impact to the RAE. They offered detailed commentaries on a wide range of aspects of departmental life that echoes their accounts of individual impacts of the RAE. For example, the impact of RAE 2008 processes on the work 
climate for research was described in terms of encouraging competition (rather than collaboration) among individuals, and creating divisiveness among categories of staff. Respondents accused the processes connected with the RAE of generating anxiety and a feeling of threat, of corroding confidence, of shifting emphasis from intrinsic to extrinsic motivation to do research, and of affecting professional identities by forcing people to make stark choices about their main area of work (teaching, research or administration). Some of the respondents noted tensions and resentment between staff whose work had been selected and those not selected for entry to the RAE; staff with lower and higher teaching loads; staff who had been core to the development of departmental RAE strategies vs other staff; and "junior" vs "senior" staff:

"RAE 2008 caused a real bifurcation between those who taught and those who researched in my research-intensive university. One awful piece of management terminology there referred to staff who were 'research active' or 'research dead"' (senior academic).

"Competitiveness, jealousy and back-biting" (professor, post-1992 institution, former polytechnic)

"There was a feeling of nervousness and anxiety about being included or not, with people who were not being included feeling demoralised and cheated; especially people who had worked very hard to get publications but were told that these were not good enough" (senior lecturer, middle management role, pre-1992 institution, 1994 group)

RAE 2008 had been perceived by many as a source of excessive pressure based on unreasonable expectations by departmental and institutional management, and a mechanism for managerialisation and bureaucratisation of academic life. This meant not only wasteful investment of time and effort in preparing for the exercise, but, more importantly, ever tighter monitoring of research activity ("hardline" performance management). A consequence of this process was a loss of autonomy in research, ranging from decisions about research agendas and potential funders, to the micromanagement of research processes:

"We were micromanaged without any concern for the academic content of our work" (senior lecturer, pre-1992 institution)

"Inflated expectations [of the $\mathrm{HEl}$ ] of the scale, scope and quality of research that is attainable within the institutional context" (professor, departmental management role, post-1992, former polytechnic). 
The focus (under the influence of the RAE) on outputs and research activity was again seen as detrimental to other activities, particularly teaching and supervision, but also administration, leadership, extra-curricular activities, and other scholarly activities (such as engagement with users and the wider community and professional development). Many respondents expressed concern about what they perceived as a devaluing of teaching within institutional cultures, under the influence of the RAE (see also McNay, 1997 and Jenkins, 1995 for longer-term perspectives). This "devaluing" was translated in practice into squeezing out the time available for teaching and for preparation, and/or moving towards teaching-only contracts, with consequences for the quality of the teaching activity overall. The perceived growing divide between teaching and research as departmental functions, they argued, made it more difficult to integrate them as scholarly practices.

Excessive pressure to publish (even before work was mature enough) and a narrower focus of research (prioritising "fundable" projects likely to be reported in mainstream academic journals) were seen as affecting both the overall quality of research being carried out in the department, and the value and support afforded to individual areas of research. Areas and types of research that were mentioned as negatively influenced included interdisciplinary research, developmental and action research, but also theoretical and philosophical work and longitudinal.

Respondents commented on concrete losses in departmental research capacity, under the influence of both the processes and the outcomes of RAE 2008. For example, some departments were said to have adopted pre-RAE 2008 staffing policies that combined "rationalization" via "job cuts" with the short-term recruitment of research-experienced staff (senior and junior) without fully integrating them in the department - by "poaching" staff approaching retirement from other institutions, or by employing research staff with good research output on short-term contracts that would not keep them in post beyond the RAE census date:

"bringing in 'big hitters' with no commitment to the department's overall development and range of activities" (professor, mid-management role, pre1992 institution)

"No money to employ promising staff from within the teaching profession with no research background and grow them on" (head of department, pre-1992 institution).

The sustainability of research capacity in these departments, as well as in the sender departments for the mobile staff, was problematic. Respondents also highlighted 
equal opportunities issues, such as the high proportion of early career staff not selected for the RAE submission - a fact that was seen as highly likely to affect negatively their prospects for career progression (for a detailed review of equal opportunities in RAE 2008, see Manfredi and Vickers, 2009):

"Junior researchers remaining junior with no support for writing publications because they are not eligible to enter" (fixed-term researcher, pre-1992 institution).

The post-RAE financial settlement further affected the ability of many departments that had previously been in receipt of QR money (post-RAE 2001) to maintain capacity, e.g. their "ability to make replacement appointments on core posts". "Doing well" in the rankings turned out not to be the same as doing well financially, partly due to some institutions giving more recognition to volume over rankings in internal distribution of funding post-2009, and partly due to reductions in funding at national level:

"My department did very well in the 2008 RAE but a few months later it became apparent that it did not make any difference. In fact, we found ourselves in deficit since the government significantly reduced its research funding to education departments. It is a paradox that has disillusioned many colleagues and it happened in many other departments across the country" (senior lecturer, pre-1992 institution)

Some pre-1992 institutions, particularly those that had developed considerably post2001 using sizeable QR grants, had come to rely heavily on this income in their plans for future development, and the anticipated financial outcome was from the outset very important in their RAE 2008-related decisions. As the financial outcomes became known, these pre-1992 institutions were faced with difficult decisions about their levels of staffing, research infrastructure and direction of future work. Respondents from some of the institutions that had lost QR income after RAE 2008 reported "uncertainty" and "increased anxiety about funding" (academics, pre-1992 institutions) and difficulties in financial management, staffing, and strategic planning in a changed climate for research, with consequences for the overall research strategy of the unit:

"The process has resulted in a decrease in [QR] funding for my [department]. This has led to all sorts of negative effects, including a very strong disincentive for any research which would not attract external funding at full economic cost. This effectively cuts down the kinds of research possible, and 
the kinds of funders that can be approached." (senior researcher on open contract, pre-1992 institution)

"Reduced funding has meant a small restructuring on top of a larger one. No money to employ promising staff from within the teaching profession with no research background and grow them on. Unless something happens soon in terms of allowing the recruitment of such staff education research will cease when the current old hands retire. This I see as the worst outcome of the underfunding, there can be no growth." (senior academic with management role, pre-1992 institution).

Thus, in the views of these respondents, the investment by these institutions in RAE processes did not generate the necessary financial return to ease off the pressures on staff over the next funding cycle:

"Our institution has lost lots of money despite gaining ... points for research the settlement has moved money from the most research active to those with more modest research cultures" (reader, pre-1992 institution).

Respondents from institutions with only marginal gain also reported problems, due to insufficient funding for the level of activity required to continue to support and develop their research culture and environment:

"In reality the funding changes have still meant a cut in budget despite strong performance" (research administrator, pre-1992 institution with increased QR)

In contrast, some participants from institutions newer to RAE processes declared that their departments had entered the RAE for "reputation and standing" (senior manager, post-1992 institution), more than they had for additional income, which had been projected to be minimal, if any. For example, at the time of submission decisions, aiming at or having recently achieved the status of "university" would have been sufficient motivation for former colleges/ teacher training institutions to find participation in the RAE meaningful and a booster of "confidence in bidding for external research funding" (senior academic, college). Nonetheless, once the postRAE financial settlement was made public, all departments were keen to ensure that even modest QR gains were reflected in their departmental budgets - with some allowance for small HEl-level top-slicing. One respondent notes:

"Receipt of HEFCE research funding for the very first time! Generates some enthusiasm for REF." (senior academic, post-1992 institution)

The main reason given by participants for this rise in the perceived importance of the 
financial outcome post-, relative to pre-, settlement was that post-2008 RAEendorsed "standing" became not just a prize, but also a responsibility. Thus, having invested in RAE processes with some degree of success, a department would now be to some extent committed to continue to support its research culture. This commitment was asserted despite concomitant concerns about the increased level of pressure, induced by ever-stricter performance management mechanisms, on individual staff.

A term used by participants in the interview component of the study was "RAE-ability" of departments - the institutional equivalent of "RAE-entryability" (professor, pre1992 institution) of individual researchers. Some of the post-1992 institutions, in particular those from countries other than England, described their decision to enter the RAE as a form of proving to themselves, to their university, and to the local community that they were "RAE-able" as a collective, i.e. that at least some of their research was of comparable standard to that in institutions with longer-established research environments:

"Benchmarking against other institutions is probably a useful bargaining tool in securing a profile for the department and an acceptance of its importance" (professor with management role, post-1992 institution)

"Recognition in [the] University of the contribution of educational research to the wider profile - reassessment of funding allocations to underpin [the] resource needed to continue our work" (professor, post-1992 institution).

\section{Perceptions of field-level impacts}

One of the survey questions asked respondents to rate the strength and direction of perceived impact (since 2005) of a range of agencies, processes and structures on education research as a field, from governmental research policy to immediate institutional contexts. Each of the factors listed were perceived by a minimum of $67 \%$ of respondents ( $n=131$ ) as having some bearing (be it positive, negative, or mixed) upon education research (see Figure 3). The influences endorsed by the lowest percentage of participants were those of the specific patterns of national research systems (21\% reported "no impact") and of the activity of learned societies (16\% "no impact"). The influences endorsed by the largest proportion of respondents were those of the processes leading up to RAE 2008 (89\% reported perceptions of some form of impact) the rating and funding outcomes of RAE 2008, and the structures, strategies and resource policies of individual HEls (each with $88 \%$ reports of impact). 
Those respondents who reported some impact tended to be most negative about the influence of funding councils' funding formulae ( $33 \%$ negative impact) and, interestingly, about the processes leading up to the RAE 2008 (32\% negative perceptions). The most benign influences were deemed to have been those of the learned societies (39\% positive, only $4 \%$ negative) and, to lesser extent, those of departmental strategies, policies and structures (28\% positive).

Figure 3. Factors influencing education research as a field, 2004-2009

(as \% of total respondents, $n=131$; see response scale in legend)

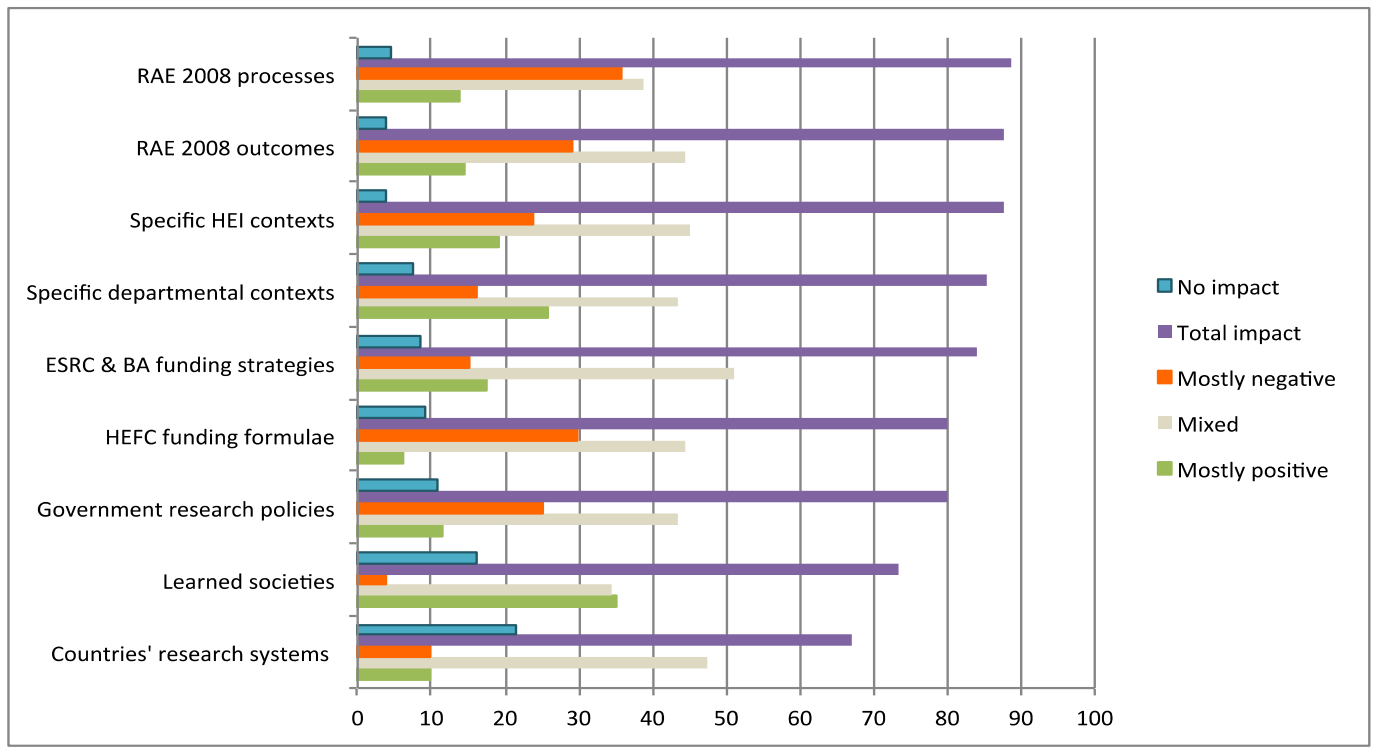

Overall, the respondents expressed strong concern about the impact of RAE 2008 on education research as a field. Respondents were the least optimistic about RAE 2008's influence on supporting positive climates in education departments and improvements in teaching. In comparison, they were somewhat less pessimistic about the fairness of Education Sub-Panel's judgments across different types of research and in all home countries (see Figure 4). In their responses to a separate question about how harsh or generous they thought the assessment had been, 74\% of the respondents $(n=131)$ declared that it had been "broadly in line with [their] own assessment". 
Figure 4. Overall views of RAE impacts

(as \% of total respondents, $n=131$; see response scale in legend)

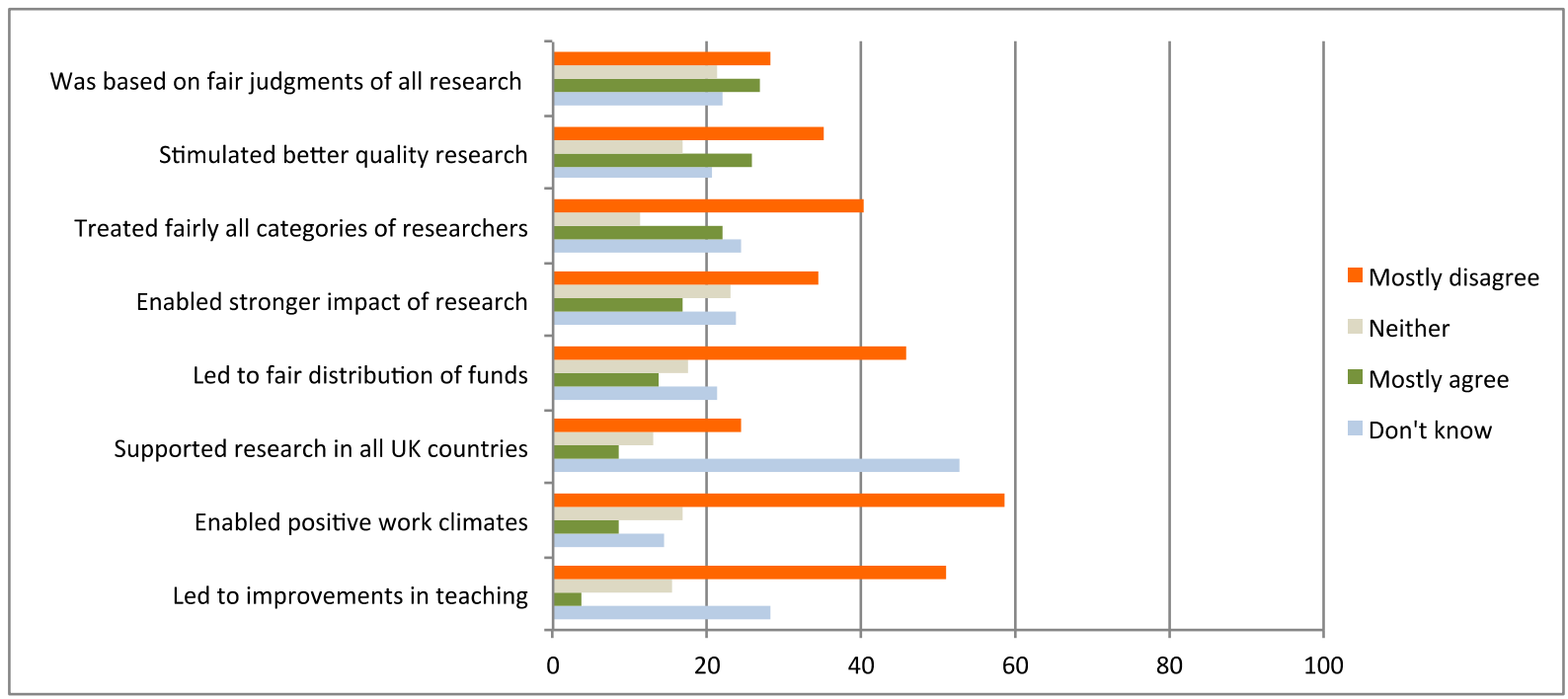

The respondents' judgments of the overall impact stretched from a perceived "general rise in quality (which I think was real, and not just the result of talking ourselves up)" (professor, pre-1992 institution) and "higher order thinking and writing" (junior researcher, pre-1992 institution)

to the RAE "having led" to

"a narrowness and intellectual impoverishment of educational research in the UK" (lecturer, management role, pre-1992 institution).

Despite offering some initial encouragement to emerging research cultures in education departments to develop, the overall financial impact of RAE 2008 on the field of education was described as detrimental to its growth and sustainability. The "worrying" financial outcome had to do with the impact of selectivity on the total size of $Q R$ resources available to education, rather than with their distribution, which meant that

"pressure to be selective was intense - led to fewer staff being returned - but education panel still rated quality of education very low compared to other panels. This, plus STEM protection, reduced money to Education, so selectivity benefited very few - even among those who did well" (professor, post-1992 institution with increase in funding).

The "real" overall impact of the RAE was deemed by respondents to be that on the relationship between educational research and educational practice and policy, an issue that was seen as more important than concerns about departmental finances and individual work and well-being. They pointed out that education departments 
across the country are an integral part of the development and reflective evaluation of communities of educational practice and policy; if the vitality of research in education is affected, the impact will ripple throughout the education system:

"We certainly need to assess the "real" impact of the RAE/REF beyond selfish concerns: e.g. on users, partners, students, intended beneficiaries, nongovernment funders (e.g. JRF, Oxfam, schools), and the quality of research and dissemination" (lecturer, pre-1992 institution).

More detailed discussion of the implications of performance-based funding for education research as a field is offered in Whitty et al (2012) and in a forthcoming paper reporting findings from the interviews component of this study.

\section{DISCUSSION AND CONCLUSIONS}

The survey findings presented in this paper suggest that the RAE has affected differently different levels of the system; for example, one respondent commented that RAE 2008 processes had more implications at individual than departmental level, while the opposite was true in the case of RAE outcomes. Overall, the picture of RAE 2008 painted by the respondents to this study was not as evenly negative as some of the literature on prior RAEs suggested. Across the board, there was a sense that the RAE had been only one (albeit important) of the factors that had accentuated a sense of uncertainty already exacerbated in conditions of crisis, and had made planning for the long term difficult. The fact that the accounts of positive and negative impacts covered the same substantive areas stands to show that any "impacts" of the RAE have been not only mostly indirect, but also mixed, even within the same institution or category of institutions. The mixed response may also reflect the mode of operation of the RAE as a governing technology, which is based on devolved responsibility via peer review, split 'steering' between government and institutional management, and build-up of commitment as individuals and institutions invest in the protracted process of interpreting the guidelines, preparing the submissions, and managing the uncertainty of outcomes.

Despite the inclusive definition of research provided in the RAE guidance, many have argued that the exercise has been conducive to increased "segmentation" (Furlong, 2013:91) of the field of education research. The segmentation is identified not only among different traditions of research (with applied research being arguably better served by the 2008 exercise than by its predecessor, analysed in Oancea, 2008), but more markedly among types of institutions, academic functions, and academic 
markets. In this line of argument, nationally and globally, and like any ranking system, the RAE has operated as an incentive for the creation and consolidation of a global "employment market for the research elite" Furlong, 2013:96) and of tiered knowledge markets for research.

At system level, the RAE has been one of the drivers of increased institutional differentiation, with mission statements drawing a separation between research intensity and, for example, regional and community service, including teacher education provision, in order to position institutions in particular functional "niches". Internally, this separation is mirrored by the bifurcation between teaching and research functions described by respondents to this study (echoing McNay, 1997), partly as a consequence of RAE-induced pressures to sharpen contractual terms as a basis for selective reporting of research activity. These trends were also highlighted in a review of the state of education research as a field (Whitty et al, 2012), which discussed recent attempts to counter increasing segmentation, for example through the use of concentration of funding as a mechanism to prompt collaboration, and by embedding corporate mechanisms of management and accountability into research organisations. The question arises whether the forces at play in these dynamics of the field of education are "segmenting" forces, or forces of functional differentiation of loosely-coupled systems - in the latter case, top-down efforts to manage collaboration by means of "mechanical integration" (Blatter, 2011) of research activity are unlikely to be effective.

The development of transinstitutional, transnational and transdisciplinary networks and other "collective spaces for academic life" in the field of education (Furlong and Lawn, 2010) has acted in part as a compensatory mechanism for the recent financial strain on academic institutions, providing alternative opportunities for funding and collaboration. At the same time, however, and in conjunction with diverse regulatory attempts at international level, it has left untouched the erosion of the visibility of education research as both a source of insights for local and national practice and policy, and an area of priority for research policy and funding.

To this day, the RAE remains one of the widest-known instances of what Coryn describes as a "Type I" mechanism for evaluating publicly funded research- a "largescale performance/judgement-based exercise" (2009, p. 62). According to Besley and Peters (2009), the exercises marked a shift from bureaucratic-professional to consumer-managerial accountability in higher education, and from disciplinary, to performative regimes of power (McKenzie, 2001). Rather than enabling the seamless merging of academic values and administrative priorities suggested in the guidance 
documents, the succession of RAEs has created the context in which performative accountability routines and their associated focus on research-extrinsic goods and re-presentation of performance (Oancea, 2008) were not just internalized at system, institutional, and individual levels, but became constitutive of higher education research.

As part of these processes, the re-description of performance management "as ars poetica of organizational practice" (McKenzie, 2001:7), within "the policy template of the knowledge economy" (Besley and Peters, 2009: 34) and supported by the normative practices of efficiency, effectiveness and quality (Lyotard, 1984), enabled the utilization of

soft psychotherapeutic technologies in the affective domain, alongside peer review mechanisms and collegial exchange, and in combination with simple counts, computer and/or accounting methodologies (including the weighting and arithmeticisation of soft variables like 'reputation') to produce departmental, faculty, and institutional performance 'profiles' and institutional, national and international league tables (Besley and Peters, 2009: 34-35).

In other words, it enabled performance management and its associate techniques including the assessment of performance, benchmarking, branding, quality assurance, "best practice", and accountability procedures - to turn into prominent governance technologies for universities and for national and international research systems and networks (D'Andrea and Gosling, 2005). This turn has been subtle and "seductive" (Ozga, 1998) and has involved tensioning of academic identities through combinations of (individual and institutional) self-regulation and disciplining, of selfexamination and audit, of self-construction and co-implication or co-option (Harley, 2002, Morley, 2001) of academics and higher education administrators: in Foucault's terms, through the "versatile equilibrium" between technologies of self and technologies of domination, or the "subtle integration of coercion-technologies and self-technologies" (1993:204). The data presented in this paper highlighted this versatile balance of tensions in the operation of the RAE as a governing technology.

Embedded in the notion of performance is the possibility (depending on conditions) of at least partial decoupling between the strategic "artifactuality" of the performance itself, and the constructed social reality of the performer and of the audience. The measurement and assessment of performance, thus, "involves multiple mutual constructions of reality" through "ever more nuanced data assemblages" (Kelly and Burrows, 2012: 148). The respondents' subscribing to a notion of intelligent 
accountability as a possible legitimation for the RAE was offset by their resentment of rigid regimes of piecemeal performance measurement; their appreciation of the exercise's procedural transparence at national level was partly offset by concern about its reported opaqueness at institutional level; their propensity to gather and analyse system and institutional level data, by surveillance anxiety; their trust in the value of peer review, by awareness of game-playing; and their support for inclusive definitions of research and for discipline-specific interpretations of its quality, by frustration in the face of performance-driven recalibration of research agendas and structures. It is this complex configuration of overlapping, multiple ambivalences of the RAE as a governance technology that seems to account for the mixed picture of the exercise's impacts revealed by this study, at system, field, institutional, and individual level.

\footnotetext{
Acknowledgements newsletter, Research Intelligence (Oancea, 2011).

Contact details

Dr Alis Oancea, University of Oxford, alis.oancea@education.ox.ac.uk.
}

I would like to thank the respondents to this study for their openness and honesty. I am grateful to John Furlong and David Bridges for their direct contribution to the study, to Margaret Brown, lan McNay, John Gardner, lan Menter, and Sue Davies for their active role as members of the study's advisory board, to Jenny Ozga for her comments on an earlier draft of this paper, and to the helpful anonymous reviewers. Thanks are also due to the study's funders, BERA and UCET. Earlier versions of parts of this paper were circulated as a report (Oancea, 2010b) and in BERA's

\section{References}

Bang. H. (2003) (Ed.) Governance as Social and Political Communication.

Manchester: Manchester University Press.

Besley and Peters (2009) Neoliberalism, performance and the assessment of educational research quality: Comparing United Kingdom, Australia and New Zealand. In: T. Besley (Ed) Assessing the Quality of Educational Research in Higher Education. International perspectives. Rotterdam: Sense, pp. 27-48. Blatter, J. (2012) Forms of Political Governance: Theoretical Foundations and Ideal Types. Working Paper 07, Department of Political Science, University of Lucerne.

Bridges, D. (2009) Assessing the quality of research in higher education: The United Kingdom Research Assessment Exercise. In: T. Besley (Ed) Assessing the Quality of Educational Research in Higher Education. International perspectives. Rotterdam: Sense, pp. 85-104. 
Brown, M. (2007) On promoting rigour-a response. Journal of Education Policy, 22(3), 353-356.

Brown, S. (2008) Research assessment in higher education: The impact on institutions, staff and educational research in Scotland. ACCESS: Critical Perspectives on Communication, Cultural \& Policy Studies, 27 (1 \& 2), 141 151.

Coryn, C.L.S. (2009) Research governance by evaluation: A meta-evaluation of international systems for evaluating government-funded research. In: T. Besley (Ed) Assessing the Quality of Educational Research in Higher Education. International perspectives. Rotterdam: Sense, pp. 59-84.

Currie, J. (2008) The Research Assessment Exercise in Hong Kong: Positive and negative consequences. International Education Journal: Comparative Perspectives, 9(1), 53-68.

Dean, M. (2010) Governmentality: Power and rule in modern society. 2nd ed. London: Sage.

Dadds, M. and Kynch, C. (2003) The impact of the RAE 3b rating on educational research in teacher education departments. Research Intelligence, 84.

Donovan, C. (2005) The governance of social science and everyday epistemology. Public Administration, 83(3), 597-615.

Elton, L. (2000) The UK RAE: Unintended consequences. Higher Education Quarterly, 54(3): 274-83.

Epstein, D., Boden, R., Deem, R., Rizvi, F, and Wright, S. (2008) Geographies of Knowledge, Geometries of Power: Framing the future of higher education. London: Routledge.

Foucault, M. (1993) About the beginning of the hermeneutics of the self: Two lectures at Dartmouth (17 and 24 November 1980, ed. M. Blasius). Political Theory, 21(2): 198-227.

Foucault, M. (2007) Security, Territory, Population. London: Palgrave

Furlong, J. (2013) Education: An anatomy of the discipline. London: Routledge.

Furlong, J. and Lawn, M. (2010) (Eds) Disciplines of Education: Their role in the future of education research. London: Routledge.

D'Andrea, V, and Gosling, D. (2005) Improving Teaching and Learning in Higher Education. A whole institution approach. Maidenhead: Open University Press.

Harley, S. (2002) The impact of research selectivity on academic work and identity in UK universities. Studies in Higher Education, 27(2), 187-205.

HEFCE (2009) Recurrent grants for 2009-10. Higher Education Funding Council for England, 08/2009, March. 
Henkel, M. (2000) Academic Identities and Policy Change in Higher Education. London: Jessica Kingsley.

Holligan, C., Wilson, M. and Humes, W. (2011) Research cultures in English and Scottish university education departments: An exploratory study of academic staff perceptions. British Educational Research Journal, 37(4): 713-734.

Jenkins, A. (1995) The Research Assessment Exercise, funding and teaching quality. Quality Assurance in Education, 3(2): 4 - 12.

Kelly, A. and Burrows, R. (2011) Measuring the value of sociology? Some notes on performative metricization in the contemporary academy. The Sociological Review, 59: 130-150.

Lucas, L. (2006) The Research Game in Academic Life. Maidenhead: SRHE/Open University Press.

Lyotard, J-F. (1984) The Postmodern Condition: A report on knowledge. Minneapolis, MN: University of Minnesota Press.

Manfredi, S. and Vickers, L. (2009) 'The impact of the process to promote equality and diversity in the RAE 2008'. Equality Challenge Unit: London.

McKenzie, J. (2001) Perform or Else: From discipline to performance. London: Routledge.

McNay, I. (1997) The Impact of the 1992 RAE on Institutional and Individual Behaviour in English Higher Education. Bristol: HEFCE

McNay, I. (2003) Assessing the assessment: An analysis of the UK Research Assessment Exercise, 2001, and its outcomes, with special reference to research in education. Science and Public Policy, 30(1),47-54.

Morley, L. (2001) Subjected to review. Engendering gender and power in higher education. Journal of Education Policy, 16(5), 465-78.

Morley, L. (2003) Quality and Power in Higher Education. Maidenhead: Open University Press.

O'Neill, O. (2002) A Question of Trust: The BBC Reith Lectures 2002. Cambridge: Cambridge University Press.

Oancea A. (2007) From Procrustes to Proteus: Trends and practices in the assessment of education research. International Journal for Research Methods in Education, 30(3), 243-269.

Oancea, A. (2008) Performative accountability and the UK Research Assessment Exercise. ACCESS: Critical Perspectives on Communication, Cultural \& Policy Studies, 27 (1 \& 2), 153-173. 
Oancea, A. (2010a) Research assessment in the United Kingdom: Issues of concern. In: International Social Science Council (2010) World Social Science Report. Paris: UNESCO.

Oancea, A. (2010b) The BERA / UCET Review of the Impacts of RAE 2008 on Education Research in UK Higher Education Institutions. Written with advice from J. Furlong and D. Bridges. Macclesfield: UCET/BERA.

Oancea, A. (2011) More, for less? Education research in the current financial and accountability contexts. Research Intelligence, 114, 6-7.

Olssen, M. (2002) The Neo-liberal Appropriation of Tertiary Education Policy in New Zealand: Accountability, research and academic freedom. Wellington: New Zealand Association for Research in Education.

Olssen, M. (2011) The strange death of the liberal university: Research assessment and the impact of research. In: R. King, S. Marginson and R. Naidoo (Eds) Handbook on Globalization and Higher Education. Cheltenham: Edward Elgar.

Ovseiko, P.V., Oancea, A., and Buchan, A.M. (2012) Assessing research impact in academic clinical medicine: A study using Research Excellence Framework pilot impact indicators. BMC Health Services Research, 12:478.

Ozga, J. (1998) The entrepreneurial researcher: Re-formations of identity in the research marketplace. International Studies in Sociology of Education, 8:2, 143-153.

Power, M. (1997) The Audit Society: Rituals of verification. Oxford: Oxford University Press.

RAE (2005) Guidance on submissions. REF RAE 3/2005, June.

Ranson. S. (2003) Public accountability in the age of neo - liberal governance. Journal of Education Policy, 18:5, 459-480.

Shore, C. and Wright, S. (2000) Coercive accountability. The rise of audit culture in higher education. In: M. Strathern (ed) (2000) Audit Cultures. Anthropological studies in accountability, ethics and the academy. London: Routledge, 57-89.

Shore, C. and Wright, S. (2004) Whose accountability? Governmentality and the auditing of universities. Parallax, 10(2): 100-116.

Talib, A. (2001) The continuing behavioural modification of academics since the 1992 Research Assessment Exercise. Higher Education Review, 33: 30-46.

Times Higher Education (2008) RAE 2008: The results. http://www.timeshighereducation.co.uk/404786.article (accessed 30 May 2013). 
Thomas, H.G. (2001) Funding mechanism or quality assessment: responses to the Research Assessment Exercise in English institutions. Journal of Higher Education Policy and Management, 23(2), 171-79.

Warde, A. (1996) The effects of the1992 RAE. Network. Newsletter of the British Sociological Association, 64:1-2.

Webb, T. (2005) The anatomy of accountability. Journal of Education Policy, 20(2), 189-208.

Appendix 1. Examples of survey questions 
1. At INDIVIDUAL level, under the influence of RAE 2008 the following aspects of my own work and career changed:

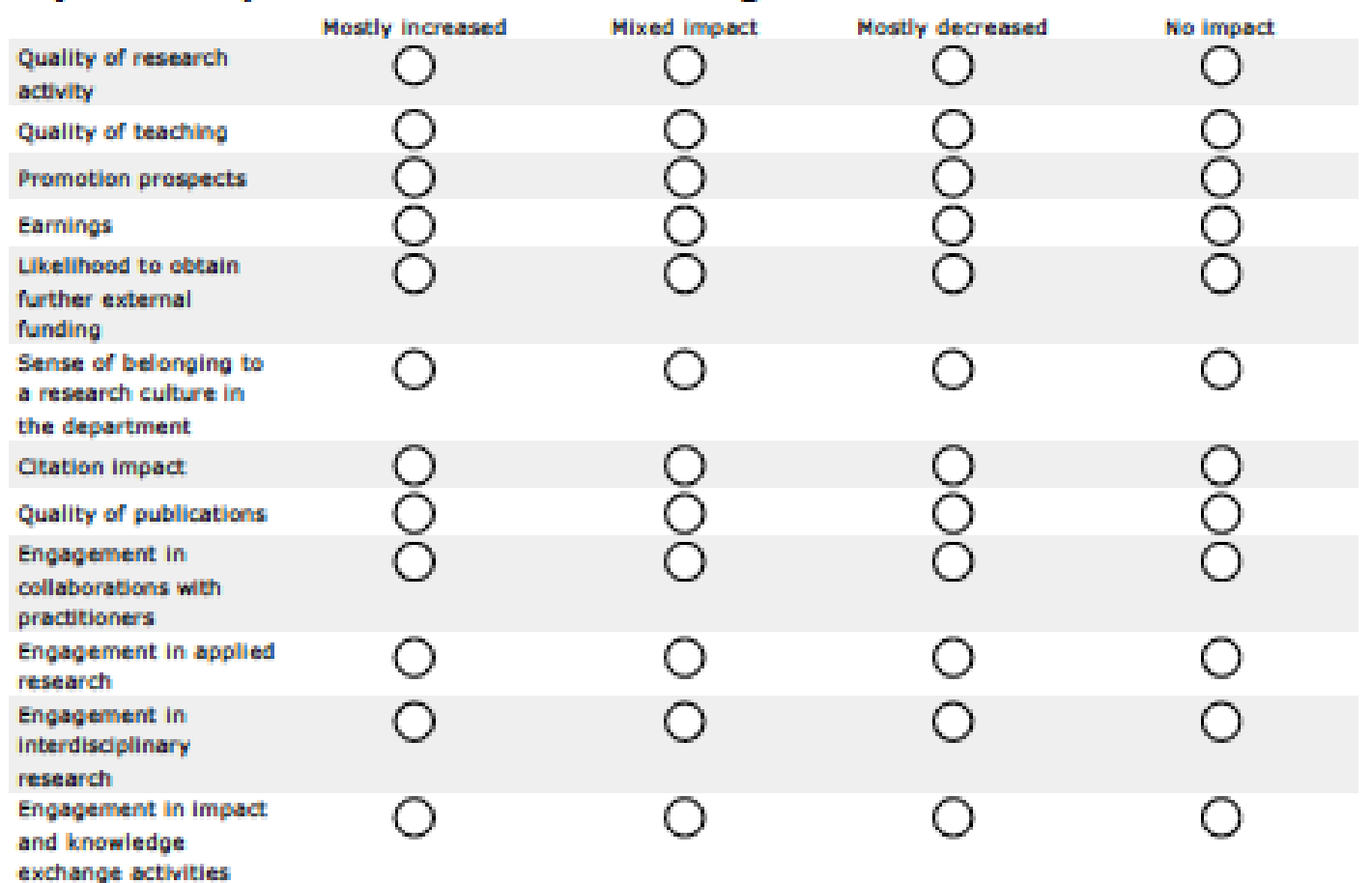

2. What are the three most significant aspects of your work and career that have been POSITIVELY affected by the $\mathbf{2 0 0 8}$ RAE? Please explain and give examples.

3. What are the three most significant aspects of your work and career that have been NEGATIVELY affected by the 2008 RAE? Please explain and give examples.

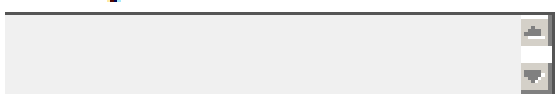

10. Please add any further examples and comments in the text box below. In particular, we would welcome comments on whether the impact of the PROCESSES leading up to submitting to RAE 2008 was different to the impact of the OUTCOMES of RAE 2008 (quality profiles and funding). 
Appendix 2. Sample description

\begin{tabular}{|c|c|c|c|}
\hline \multicolumn{4}{|l|}{ Current post } \\
\hline & Research - junior & & 13 \\
\hline & Lecturer & & 61 \\
\hline & Research senior & & 44 \\
\hline & \multicolumn{2}{|c|}{ Research administration/ other } & 5 \\
\hline \multicolumn{4}{|c|}{ Current contract } \\
\hline & Fixed-term & & 9 \\
\hline & Open/rolling & & 9 \\
\hline & Permanent & & 106 \\
\hline \multicolumn{4}{|c|}{ Decision-making responsibilities } \\
\hline & \multicolumn{2}{|c|}{ Senior management } & 32 \\
\hline & \multicolumn{2}{|c|}{ Mid-management } & 26 \\
\hline & \multicolumn{2}{|c|}{ Project management and admini } & 15 \\
\hline & None & & 57 \\
\hline \multicolumn{4}{|c|}{ Funding history } \\
\hline & PI/grant holder & & 72 \\
\hline & \multicolumn{2}{|c|}{ Researcher (not PI) } & 26 \\
\hline & \multicolumn{2}{|c|}{ Other involvement } & 9 \\
\hline & None & & 19 \\
\hline \multicolumn{4}{|l|}{ Age group } \\
\hline & 45 and under & & 29 \\
\hline & $46-55$ & & 46 \\
\hline & 56 and over & & 49 \\
\hline \multicolumn{4}{|l|}{ Sex } \\
\hline & Female & & 63 \\
\hline & Male & & 53 \\
\hline & Prefer not to say & & 5 \\
\hline \multicolumn{4}{|c|}{ Submitted to RAE 2008} \\
\hline & Yes & & 93 \\
\hline & No & & 33 \\
\hline \multicolumn{4}{|c|}{ Current way of working } \\
\hline & Lone researcher & & 55 \\
\hline & Part of team & & 65 \\
\hline \multicolumn{4}{|c|}{ Inter/disciplinarity } \\
\hline & \multicolumn{2}{|c|}{ Disciplinary work mostly } & 53 \\
\hline & \multicolumn{2}{|c|}{ Multi/interdisciplinary work } & 65 \\
\hline \multicolumn{4}{|c|}{ Self-rated knowledge of RAE } \\
\hline & Excellent/good & & 72 \\
\hline & Average/fair & & 44 \\
\hline & Poor & & 7 \\
\hline \multicolumn{4}{|c|}{ Self-rated practical experience of RAE processes in institution } \\
\hline & Excellent/good & & 77 \\
\hline & Average/fair & & 40 \\
\hline & Poor & & 9 \\
\hline Type of curre & & & \\
\hline & Pre-1992 & & 99 \\
\hline & Post-1992 & & 24 \\
\hline Country of cu & & & \\
\hline & England & & 99 \\
\hline & Scotland & & 12 \\
\hline & Northern Ireland & & 11 \\
\hline & Wales & & 1 \\
\hline Outcome of $\mathrm{R}$ & istitution & & \\
\hline & Better & & 46 \\
\hline & No change & & 21 \\
\hline & Worse & & 32 \\
\hline & Not known & & 24 \\
\hline
\end{tabular}

